\title{
Efficient computation of absent words in genomic sequences Julia Herold ${ }^{1}$, Stefan Kurtz ${ }^{2}$ and Robert Giegerich*1
}

\author{
Address: ${ }^{1}$ Center of Biotechnology, Bielefeld University, Postfach 1001 31, 33501 Bielefeld, Germany and ${ }^{2}$ Center for Bioinformatics, University \\ of Hamburg, Bundesstrasse 43, 20146 Hamburg, Germany \\ Email: Julia Herold - jherold@cebitec.uni-bielefeld.de; Stefan Kurtz - kurtz@zbh.uni-hamburg.de; Robert Giegerich* - robert@techfak.uni- \\ bielefeld.de \\ * Corresponding author
}

Published: 26 March 2008

BMC Bioinformatics 2008, 9:167 doi:10.1186/147/-2105-9-167

This article is available from: http://www.biomedcentral.com//47I-2105/9/167

C 2008 Herold et al; licensee BioMed Central Ltd.

This is an Open Access article distributed under the terms of the Creative Commons Attribution License (http://creativecommons.org/licenses/by/2.0), which permits unrestricted use, distribution, and reproduction in any medium, provided the original work is properly cited.
Received: 8 November 2007

Accepted: 26 March 2008

\begin{abstract}
Background: Analysis of sequence composition is a routine task in genome research. Organisms are characterized by their base composition, dinucleotide relative abundance, codon usage, and so on. Unique subsequences are markers of special interest in genome comparison, expression profiling, and genetic engineering. Relative to a random sequence of the same length, unique subsequences are overrepresented in real genomes. Shortest words absent from a genome have been addressed in two recent studies.

Results: We describe a new algorithm and software for the computation of absent words. It is more efficient than previous algorithms and easier to use. It directly computes unwords without the need to specify a length estimate. Moreover, it avoids the space requirements of index structures such as suffix trees and suffix arrays. Our implementation is available as an open source package. We compute unwords of human and mouse as well as some other organisms, covering a genome size range from $10^{9}$ down to $10^{5} \mathrm{bp}$.

Conclusion: The new algorithm computes absent words for the human genome in 10 minutes on standard hardware, using only $2.5 \mathrm{Mb}$ of space. This enables us to perform this type of analysis not only for the largest genomes available so far, but also for the emerging pan- and meta-genome data.
\end{abstract}

\section{Background}

\section{Sequence statistics and unique substrings}

Word statistics is a traditional field of genome research. For word-length 1, GC-content is a basic characteristic noted for each organism, and dinucleotide relative abundance profiles provide a reliable genomic signature [1]. Dinucleotide content also distinguishes natural RNA from random sequences [2]. Trinucleotide (codon) usage can reliably predict bacterial genes [3] even in the presence of horizontal gene transfer. Short palindromic words mark the characteristic sites of restriction enzymes in bacteria, and are therefore under represented in bacterial genomes
[4]. A theory of over- as well as under-represented words has been laid out in $[5,6]$.

Unique words are of particular interest. They provide sequence signatures, and microarray probes are often designed to match them. Unique sequences from several genomes exhibiting a perfect match serve as reliable anchors in a multiple genome alignment [7]. Recently, Haubold et al. [8] addressed the problem of efficiently computing shortest unique substrings (using their terminology) in a sequence, and provided a program called SHUSTRING for this purpose. Using this program, they 
found that there is typically much more unique sequence in a genome than one would expect in a random sequence of the same length. While this observation by itself is not a surprise, given the repetitive nature of genomes, their approach and software allows to quantify this fact. Furthermore, they found unique words to be significantly clustered in upstream regions of genes in human and mouse.

\section{Absent words}

One may take such investigations farther and investigate words that do not occur in a genome. We suggest the term "unwords" for shortest words from the underlying alphabet that do not show up in a given sequence.

A first approach at the unwords problem was recently presented by Hampikian and Andersen [9]. Their motivation was to "discover the constraints on natural DNA and protein sequences". However, there is no evidence that such constraints exist. The absence of certain shortest words in a sequence data base, no matter what (finite) size it has, is a mathematical necessity. Speculations about negative selection against certain words have been refuted convincingly in [10]. There, it is shown that human unwords computed in [9] can be explained by a mutational bias rather than negative selection.

Still, there is twofold interest in the capability of efficiently computing unwords.(1) Statistically, it is interesting to see how length and number of unwords in a given genome deviates from expectation in random sequences. (2) Practically, it is useful to know all the unwords when a genome or chromosome is to be extended by insertion of foreign DNA. Combinations of unwords can directly serve as tags that are guaranteed to be unique in the modified DNA sequence.

\section{Software for unwords computation}

Unfortunately, the software presented in [9] is slow and difficult to use: It reads Genbank files rather than the more space efficient Fasta format - and space matters a lot when dealing with genomes as large as human and mouse. It runs an internal conversion routine for over 50 minutes before starting unwords computation. The program generates an excessive number of files that may break your file systems. The $\mathrm{C}$ code is platform dependent and internal constants must be adapted. Finally, the human unwords data computed with the program according to [9] appear to be incomplete (and hence incorrect).

In order to make unwords computation possible in an efficient and reliable way, we present here a new algorithm and the software implementing it. Efficient computation of unwords can be done from an index data structure such as a suffix tree or an (enhanced) suffix array
[11]. For example, in [8] a suffix tree was used to compute unique substrings. In fact, our first unwords-program was an extension to the VMATCH software [12], which is based on enhanced suffix arrays. However, index data structures must be built in memory and are space-consuming. Hence, we developed a direct approach that works more efficiently, because the overall sequence need not be kept in main memory. Computing the unwords of the human genome, for example, takes about 10 minutes computation time on a Linux PC with a single $2.4 \mathrm{MHz}$ $\mathrm{CPU}$. The space requirement is 2.5 megabytes.

In this article, we describe the new program UNWORDS and report its application to the genomes of human, mouse, and other organisms, covering a genome size range from $10^{9}$ down to $10^{5} \mathrm{bp}$.

\section{Results \\ Problem statement}

Let $\Sigma$ be a finite alphabet of at least two letters. Let $|\Sigma|$ denote the cardinality of $\Sigma$. In genome analysis, $\Sigma=\{a, c$, $\mathrm{g}, \mathrm{t}\}$ and $|\Sigma|=4$. A word is a sequence of letters from the alphabet. The terms "word" and "sequence" are equivalent, but are used here to indicate that a word is short and a sequence is long. $|w|$ denotes the length of a word. If $|w|$ $=q$, we speak of a $q$-word.

A word $w$ over $\Sigma$ is an unword of a sequence $G$ if (1) it does not occur as a substring of $G$, and (2) all words over $\Sigma$ shorter than $w$ do occur in $G$. Note that the unword length is uniquely defined for a given genome $G$.

The built-in minimality requirement in this definition is motivated by the fact that when $w$ is an unword of length $q$ in $G$, it has $2|\Sigma|$ one-letter extensions that also do not occur in $G$. Therefore, asking for missing words longer than $q$ would introduce a substantial proportion of redundant results.

Similar to shortest unique substrings, the length of unwords is expected to increase with genome size. For fixed unword length, the number of unwords is expected to decrease while $|G|$ increases. Given $G$, let $q$ be the unword length. It is easy to see that $1 \leq q$. To derive an upper bound on $q$, let $w$ be a shortest unique substring in $G$ and let $\ell=|w|$. Consider the following cases:

- If $|w|=|G|$, then for any $a \in \Sigma$, wa is an unword. Hence $q \leq|w a|=\ell+1$.

- If $|w|<|G|$ and $w$ is not a suffix of $G$, then $w a$ occurs in $G$ for exactly one letter $a$. Hence $w b$ for any $b \in \Sigma \backslash\{a\}$ is an unword. This implies $q \leq|w b|=\ell+1$. 
- If $|w|<|G|$ and $w$ is not a prefix of $G$, then aw occurs in $G$ for exactly one letter $a$. Hence $b w$ for any $b \in \Sigma \backslash\{a\}$ is an unword. This implies $q \leq|w b|=\ell+1$.

Thus we conclude $1 \leq q \leq \ell+1$.

The problem of unword analysis of a given sequence $G$ (typically a complete genome) is to determine all unwords of G. The double-stranded nature of DNA lets unwords always show up in complementary pairs, as each word present implies the presence of its Watson-Crick complement on the opposite strand. Sometimes, however, an unword is self-complementary, and hence a "pair" represents only a single word. Therefore, we report unword numbers rather than numbers of pairs (in contrast to [8]).

Computation of $q$-word statistics for small $q$ is straightforward. Efficient computation of unwords when $q$ is unknown, however, requires more advanced techniques. Our unword analysis algorithm is described in the section on computational methods.

\section{Unword statistics}

The unword analysis problem is mathematically well defined. Unwords must exist for any sequence. The interesting question is their size and number, compared to what one would expect given the alphabet size and the length of $G$.

Let $w$ be a word of length $|w|, w[i]$ the $i$-th letter in $w, G$ a genomic sequence and $\mathbb{P}[w[i]]$ the relative frequency of nucleotide $w[i]$ in $G$. The probability for $w$ to occur by chance (i.e. at a fixed position in a random sequence $s$ of the same composition and length as $G$ ) is then $\mathbb{P}[w]=\prod_{i=1}^{|w|} \mathbb{P}[w[i]]$. The expectation value for (the number of occurrences of) $w$ in $s$ is $\mathbb{E}[w$ in $s] \approx \mathbb{P}[w] \cdot|G|$.

Calculating the probability for a word not to occur in a specific sequence is quite difficult and not much literature is available. Following Rahmann et al. [13], a good approximation of the probability can be given using the expectation value. A Poisson Distribution is expected for word counts in a genomic sequence, which is $\mathbb{P}\left[X_{w}=k\right]=\frac{\lambda(w)^{k}}{k !} \cdot e^{-\lambda(w)}$ with $\lambda(w)=\mathbb{E}[w$ in $s]$, and $k$ the number of occurrences of the word $w$. Now let $k=0$. Then

$$
\mathbb{P}\left[X_{w}=0\right]=1 \cdot e^{-1(w)}
$$

The expected number $N$ of $q$-words that do not occur is therefore

$$
N \approx|\Sigma| q e^{-\lambda(w)}
$$

As an example, for a random sequence $G$ of length $3.1 \cdot 10^{9}$ and an unword $w$ of length 14 and typical composition, we obtain a probability of $1.40082 \cdot 10^{-5}$ for $w$ not occurring in $G$. Still, the expected number of unwords of length 14 is 2590.798 , while for length 13 , it is only $5.823108 \cdot 10^{-13}$. For even shorter unwords, it is practically zero.

\section{Unwords algorithm}

For convenience, we map each of the four letters of the DNA-alphabet to an integer in the range 0 to 3 as follows: $\bar{a}=0, \bar{c}=1, \bar{g}=2, \bar{t}=3$. Moreover, for any fixed value $q$, we use a standard method to map each possible $q$-word to a number in the range $[0,4 q-1]$. That is, we define $\mathbf{j}_{q}(w)=\sum_{i=1}^{q} \overline{w[i]} \cdot 4^{q-i}$ for any $q$-word $w$. In other words, $q$-words are mapped to their rank in the corresponding lexicographic order. Substrings in $G$ containing at least one wildcard (e.g. N) are ignored. The integer value $\phi_{q}(w)$ serves as an index into a bit table $\Omega_{q}$ such that for all sequences $w$ of length $q$ we have: $\Omega_{q}\left[\phi_{q}(w)\right]=1$ if and only if $w$ occurs as a substring in the genome G. Let $\left|\Omega_{q}\right|$ denote the number of 1-entries in $\Omega_{q}$.

Initially we set all bits in $\Omega_{q}$ to 0 . This requires $O\left(\frac{4^{q}}{w}\right)$ time, where $w$ is the computer word size. Then we sweep a window of width $q$ over $G$ from left to right. For the first window $G[1 . . q]$ we determine the integer code $\phi_{q}(G$ $[1 . . q])$ as defined above in $O(q)$ time. For each of the remaining $n-q$ windows, say at start position $i+1$, we compute $\phi_{q}(G[i+1 . . i+q])$ in constant time from $\phi_{q}(G[i . . i$ $+q-1])$ according to the following equation:

$$
\boldsymbol{j}_{q}(G[i+1 . . i+q])=\left(\boldsymbol{j}_{q}(G[i . i+q-1])-4^{q-1} \cdot \overline{G[i]}\right) \cdot 4+\overline{G[i+q]}
$$

Thus the computation of the $n-q+1$ integer code requires $O(n)$ time. The multiplication and addition in can be implemented by fast bit-shift and bit-or operations. If $j$ is the current integer code and $\Omega_{q}[j]$ is 0 , then we set $\Omega_{q}[j]$ to 1 and increment a counter of the number of 1-entries in $\Omega_{q}$. This can be done in constant time. Note that once $\left|\Omega_{q}\right|=4 q$, we can stop scanning $G$. While the time requirement of this algorithm is $O\left(n+\frac{4^{q}}{w}\right)$ it uses $O(1)+2 q+$ 
$4^{q}$ bits of space, as only $q$ consecutive letters in $G$ need to be stored in memory.

If $\left|\Omega_{q}\right|=4 q$, i.e. all $4 q$ entries in $\Omega_{q}$ are 1 , then we know that all possible $q$-words occur in $G$. Hence there is no unword of length $q$ in $G$. On the other hand, if after processing all $q$-words in $G,\left|\Omega_{q}\right|<4$, there are some unwords of length $q$. If additionally $\left|\Omega_{q-1}\right|=4 q-1$, then we know that $q$ is the smallest value such that unwords of length $q$ exist. The unwords can easily be computed by determining all $j$ such that $\Omega_{q}[j]=0$. Given $j$, one determines the corresponding $q$-word $w$ satisfying $\phi_{q}(w)=j$ in $O(q)$ time. Thus the unwords are enumerated in $O\left(4^{1}+q z\right)$ time where $z$ is the number of unwords.

Let $q^{*}$ be the smallest value such that there are unwords of length $q^{*}$. Consider the possible range of values for $q$ for a given genome length $n$. Let $q^{\max }=\operatorname{rog}_{4}(n+1)$. Then $4^{q^{\max }}=4^{\left\lceil\log _{4}(n+1)\right\rceil} \geq n+1>n \geq n-q^{\max }+1$. Note that $G$ contains $n-q^{\max }+1$ substrings of length $q^{\max }$. Hence $G$ is too short to accommodate all possible $q^{\text {max }}$-words and therefore there are some unwords of length $q^{\max }$. Thus $q^{*}$ $\leq q^{\text {max }}$, i.e. we can restrict the search for $q^{*}$ to the range [1, $\left.q^{\max }\right]$.

There are basically two strategies to determine $q^{*}$. The first strategy (linear search) starts with $q=1$ and increments $q$ until $\left|\Omega_{q}\right|<4 q$. Then $q^{*}=q$. The space requirement is $O(1)$ $+2 q^{*}+4^{q *}$ and the running time is

$O\left(4^{q^{*}}+q^{*} z\right)+\sum_{q=1}^{q^{*}} O\left(n+\frac{4^{q}}{\boldsymbol{w}}\right)=O\left(4^{q^{*}}+q^{*} z\right)+O\left(q^{*} n\right)+O\left(\frac{4^{q^{*}+1}}{\boldsymbol{w}}\right)$

where $z$ is the number of unwords. Note that we have $n \geq 4^{q^{*}-1}=\frac{4^{q^{*}+1}}{4^{2}} \geq \frac{4^{q^{*}+1}}{\omega}$ under the realistic assumption that the machine word size $\omega$ is at least $4^{2}$. Hence $n$ dominates the last term in (4). Thus the overall running time for the linear search is $O\left(4^{*}+q^{*}(n+z)\right)$.

The second strategy determines $q^{*}$ by a binary search in the range $\left[1, q^{\max }\right]$, as described in Table 1 . The strategy is optimal in the sense that it tests a minimal number of possible values of $q$ before it arrives at $q^{*}$. Unfortunately, a value $q^{\prime}$ determined in line 8 of Table 1 , may or may not be modified later in the loop, which means that one has to store the corresponding table $\Omega_{q^{\prime}}$ or recompute it later. The running time of the binary search is
Table I: Algorithm for computing $q^{*}$ by a binary search strategy.

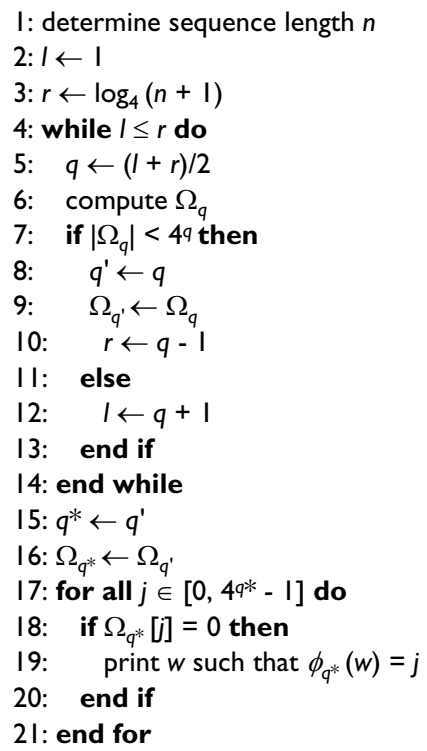

$O\left(4^{q^{*}}+q^{*} z\right)+\log _{2} q^{\max }\left(n+\frac{4^{q^{\max }}-1}{\omega}\right)$. Its space requirement is $O(1)+2 q^{\max }+4^{q^{\max }}$.

\section{Testing}

We used our first implementation (based on suffix-arrays) of an unwords algorithm to cross-validate the program presented here. Applied to the human genome, both algorithms (which are completely independent) produce the same set of unwords. This makes us sure that our set of 104 human unwords is indeed complete, in contrast to the 80 unwords reported in [9]. (If a smaller genome assembly or repeat masked sequences were used in this earlier study, more rather than less unwords should have been detected.) We computed unwords for six eucaryotic genomes: Homo sapiens, Release NCBI36 [14], Mus musculus, Release NCBIm36 [15], Drosophila melanogaster, Release 5.1 [16], Caenorhabditis elegans, Release WS170 [17], Neurospora crassa [18] and Saccharomyces cerevisiae, Release SGD1.01 [19], including nonchromosomal sequences which could not be assigned to a chromosome. Additionally, unwords for two bacterial genomes were calculated: Staphylococcus aureus subsp. aureus strain MSSA476, Refseq number NC_002953 and Mycoplasma genitalium, Refseq number NC_000908, as well as for two Archaea genomes:

Thermococcus kodakarensis, Release KOD1 [20] and Methanocaldococcus jannaschii, Release DSM 2661 [21]. Table 2 gives a summary of genome sizes and unword lengths and numbers. In Table 3, we show the unwords computed from the human genome. We also indicate the number of 
Table 2: Genome sizes (including sequences not assigned to a chromosome), the logarithm of the genome size to the base of 10 , length and number of unwords of the analyzed genomes

\begin{tabular}{|c|c|c|c|c|c|}
\hline Organism & Genome size & $\left\lfloor\log _{10}|G|\right.$ & $\left\lfloor\log _{4}|G|\right.$ & \#unwords & length \\
\hline H. sapiens & $\approx 3.1 \mathrm{~Gb}$ & 9 & 15.8 & 104 & 11 \\
\hline M. musculus & $\approx 2.7 \mathrm{~Gb}$ & 9 & 15.7 & 192 & 11 \\
\hline D. melanogaster & $\approx 132 \mathrm{Mb}$ & 8 & 13.5 & 104 & 11 \\
\hline C. elegans & $\approx 100 \mathrm{Mb}$ & 8 & 13.3 & 2 & 10 \\
\hline N. crassa & $\approx 34 \mathrm{Mb}$ & 7 & 12.5 & 2262 & 11 \\
\hline S. cerevisiae & $\approx 12 \mathrm{Mb}$ & 7 & 11.8 & 4 & 9 \\
\hline S. aureus & $\approx 2.79 \mathrm{Mb}$ & 6 & 10.7 & 248 & 8 \\
\hline T. kodakarensis & $\approx 2.08 \mathrm{Mb}$ & 6 & 10.5 & I & 8 \\
\hline M. jannaschii & $\approx 1.66 \mathrm{Mb}$ & 6 & 10.3 & 3 & 6 \\
\hline M. genitalium & $\approx 0.58 \mathrm{Mb}$ & 5 & 9.6 & 5 & 6 \\
\hline
\end{tabular}

Table 3: Unwords for the human genome and their expected number of occurrences. The four words which are also unwords for the mouse genome are shown in a box.

\begin{tabular}{|c|c|c|c|c|c|c|c|}
\hline accgatacgcg & 153 & accgttcgtcg & 153 & acgaccgttcg & 153 & acgatcgtcgg & 153 \\
\hline acgcgcgatat & 221 & acggtacgtcg & 153 & agcgtcgtacg & 153 & atatcgcgcgg & 153 \\
\hline atatcgcgcgt & 221 & atcgtcgacga & 221 & atgtcgcgcga & 153 & catatcgcgcg & 153 \\
\hline ccgaatacgcg & 153 & ccgacgatcga & 153 & ccgacgatcgt & 153 & ccgatacgtcg & 153 \\
\hline ccgcgcgatat & 153 & ccgtcgaacgc & 106 & ccgttacgtcg & 153 & cgaacggtcgt & 153 \\
\hline cgaatcgacga & 221 & cgaatcgcgta & 221 & cgaccgatacg & 153 & cgacgaacgag & 153 \\
\hline cgacgaacggt & 153 & $\theta$ & 153 & cgacgcgtata & 221 & cgacggacgta & 153 \\
\hline cgacgtaacgg & 153 & cgacgtaccgt & 153 & cgacgtatcgg & 153 & cgatcgtgcga & 153 \\
\hline cgattacgcga & 221 & cgattcggcga & 153 & cgcgacgcata & 153 & cgcgacgttaa & 221 \\
\hline cgcgcataata & 319 & cgcgcgatatg & 153 & cgcgctatacg & 153 & cgcgtaacgcg & 106 \\
\hline cgcgtaatacg & 221 & cgcgtaatcga & 221 & cgcgtatcggt & 153 & cgcgtattcgg & 153 \\
\hline cgcgttacgcg & 106 & 6 & 153 & cggtcgtacga & 153 & cgtacgaaacg & 221 \\
\hline cgtacgacgct & 153 & cgtatacgcga & 221 & cgtatagcgcg & 153 & cgtatcggtcg & 153 \\
\hline cgtattacgcg & 221 & cgtcgactatc & 221 & cgtcgetcgaa & 153 & cgtcgttcgac & 153 \\
\hline cgttacgcgtc & 153 & cgtttcgtacg & 222 & ctacgcgtcga & 153 & ctcgttcgtcg & 153 \\
\hline gacgcgtaacg & 153 & gatagtcgacg & 221 & gcgcgacgtta & 153 & gcgcgtaccga & 106 \\
\hline gcgttcgacgg & 106 & ggtacgcgtaa & 221 & $\mathbf{g}$ & 153 & gtccgagcgta & 153 \\
\hline gtcgaacgacg & 153 & taacgtcgcgc & 153 & tacgcgattcg & 221 & tacgcgcgaca & 153 \\
\hline tacgctcggac & 153 & tacggtcgcga & 153 & tacgtccgtcg & 153 & $\mathbf{b}$ & 153 \\
\hline tagcgtaccga & 221 & tatacgcgtcg & 221 & tatcgcgtcga & 221 & tatgcgtcgcg & 153 \\
\hline tattatgcgcg & 321 & tattcgcgcga & 221 & tcgacgcgata & 221 & tcgacgcgtag & 153 \\
\hline tcgatcgtcgg & 153 & tcgattacgcg & 221 & tcgcacgatcg & 153 & tcgccgaatcg & 153 \\
\hline tcgcgaccgta & 153 & tcgcgacgtaa & 221 & tcgcgcgaata & 221 & tcgcgcgacat & 153 \\
\hline tcgcgtaatcg & 221 & tcgcgtatacg & 221 & tcggtacgcge & 106 & tcggtacgcta & 221 \\
\hline tcgtacgaccg & 153 & tcgtcgacgat & 221 & tcgtcgattcg & 222 & tgtcgcgcgta & 153 \\
\hline ttaacgtcgcg & 221 & ttacgcgtacc & 221 & ttacgtcgcga & 221 & ttcgagcgacg & 153 \\
\hline
\end{tabular}


Table 4: GC content of Human, Mouse, Drosophila melanogaster, Caenorhabditis elegans, Saccharomyces cerevisiae, Staphylococcus aureus and Mycoplasma genitalium as well as the GC content of the associated unwords.

\begin{tabular}{ccc}
\hline Organism & Genome GC\% & Unword GC\% \\
\hline H. sapiens & $\approx 38$ & $\approx 45-72$ \\
M. musculus & $\approx 40$ & $\approx 54-72$ \\
D. melanogaster & $\approx 40$ & $\approx 45-90$ \\
C. elegans & $\approx 35$ & $\approx 80$ \\
S. cerevisiae & $\approx 38$ & $\approx 89-100$ \\
S. aureus & $\approx 33$ & $\approx 50-100$ \\
M. genitalium & $\approx 32$ & $\approx 66-100$ \\
\hline
\end{tabular}

occurrences expected for each unword - if the genome was a random sequence, which of course is not the case. Deviation of GC content in unwords is summarized in Table 4. Unwords for the other genomes are given in Tables 5, 6, 7, 8, 9, 10, 11, 12 .

\section{Conclusion}

Genomic unwords may not have a functional meaning, but they do have relevance in practice and in theory. When planning experiments such as large scale mutagenesis [22], a high number of markers is to be included in the inserted DNA. Such markers should be disjoint from each other and from the original genome. Given (say) 100 unwords of length 11 , we can directly compose 10,000

Table 5: Unwords for the Mouse genome.

\begin{tabular}{|c|c|c|c|c|c|}
\hline aacgcgtatcg & aatcgcgcgat & acccgcgtacg & accgcgatacg & acgaacgtcga & acgacgegata \\
\hline acgacgtacgg & acgattcgacg & acgattcgcgt & acgcgaaacga & acgcgaatcgt & acgegtcgaaa \\
\hline acgcgtcgcga & acgcgtcgeta & acggtcgtcga & acgttcgaacg & acgttcgaccg & actcgtcgcga \\
\hline atcgacgcgcg & atcgcgcgatt & atcgeggtacg & atcgtaccgcg & atcgtacgccg & atcgtcgaccg \\
\hline attacgcgcga & attacgcgcgg & attacgtcgcg & attcgcgcgta & attgcgtcgcg & cccgatacgcg \\
\hline ccgatacgcgc & ccgcgatacga & ccgcgcgataa & ccgcgcgtaat & ccgcgcgtata & ccggtcgtacg \\
\hline ccgtacgtcgt & ccgtcgaatcg & cgaatttcgcg & cgacgagcgta & cgacgcgataa & cgacgcgatac \\
\hline cgacgcgtaac & cgacggatacg & cgacgtaacgc & cgacgttaacg & cgactaacgcg & cgatacgacga \\
\hline cgatacgccga & cgatacgcgtt & cgatagtcgcg & cgatcgacgcg & cgatcgcgtaa & cgatcgtacga \\
\hline cgatcgtcgca & cgattcgacgg & cgattgacgcg & cgcatatcgcg & cgccgattacg & cgcgaaattcg \\
\hline cgcgaccgata & cgcgacgcaat & cgcgacgtaat & cgcgactatcg & cgcgatacgaa & cgcgatacgac \\
\hline cgcgatatcac & cgcgatatccg & cgcgatatgcg & cgcgatcggta & cgcgcgtaacg & cgcgcgtcgat \\
\hline cgcggtacgat & cgcgtaacgta & cgcgtatcggg & cgcgtcaatcg & cgcgtcacgta & cgegtcgatcg \\
\hline cgcgtcgatta & cgcgttagtcg & cgctcgacgta & cggacgtcgta & cggatatcgcg & cggcgtacgat \\
\hline cggcgtcgtaa & cgggcgtaacg & cggtcgaacgt & cggtcgacgat & cgtaatcgcga & cgtaatcggcg \\
\hline cgtaccgcgat & cgtacgaccgg & cgtacgatcgc & cgtacgcgggt & cgtatccgtcg & cgtatcgcgag \\
\hline cgtatcgcggt & cgtccgatcga & cgtcgaatcgt & cgtcgacgagc & cgtcgcgttaa & cgtcgcgttag \\
\hline cgtcgttacgc & cgttaacgtcg & cgttacgeccg & cgttacgcgcg & cgttcgaacgt & cgttcgaccga \\
\hline cgttgcgcgaa & cgttgcgtcga & ctaacgcgacg & ctcgcgatacg & ctcgcgtacga & gcgatcgtacg \\
\hline gcgcgatacga & gcgcgtacgac & gcgcgtatcgg & gcgtaacgacg & gcgttacgtcg & gctcgtcgacg \\
\hline gtatcgcgtcg & gtcgcgaacta & gtcgcgcgata & gtcgtacgcga & gtcgtacgcgc & gtcgtatcgcg \\
\hline gtgatatcgcg & gttacgcgtcg & taaccgcgega & taatcgacgcg & taccgatcgeg & tacgacgtccg \\
\hline tacgcgcgaat & tacgctcgtcg & tacggacgega & tacgtcgagcg & tacgtgacgcg & tacgttacgcg \\
\hline tagcgacgcgt & tagttcgcgac & tatacgcgcgg & tatcgcgcgaa & tatcgcgcgac & tatcgcgtcgt \\
\hline tatcggcgcga & tatcggtcgcg & tcatcgcgcga & tcgacgaccgt & tcgacgcaacg & tcgacgcgtaa \\
\hline tcgacgttcgt & tcgatcggacg & tcgcgacgaaa & tcgcgacgagt & tcgcgacgcgt & tcgcgattacg \\
\hline tcgcgccgata & tcgcgcgatga & tcgcgcggtta & tcgcgcgtaat & tcgcgtaccga & tcgcgtacgaa \\
\hline tcgcgtacgac & tcgegtccgta & tcggcgtatcg & tcggtacgcga & tcggtcgaacg & tcgtacgatcg \\
\hline tcgtacgcgag & tcgtatcgcgc & tcgtatcgcgg & tcgtcgaacga & tcgtcgtatcg & tcgttcgacga \\
\hline tcgtttcgcgt & tgcgacgatcg & ttaacgcgacg & ttacgacgecg & ttacgcgatcg & ttacgcgcgaa \\
\hline ttacgcgtcga & ttatcgcgcgg & ttatcgcgtcg & ttcgcgcaacg & ttcgcgcgata & ttcgcgcgtaa \\
\hline ttcgtacgcga & ttcgtatcgcg & tttcgacgcgt & tttcgtcgcga & & \\
\hline
\end{tabular}


Table 6: Unwords for the C. elegans genome.

accccccag

ctgggggggt

markers of length 22 which have a guaranteed Hamming distance from the genome of at least 2. From this supply of candidates, markers can be selected according to other criteria such as melting temperature.

Unwords analysis is fast enough to be applied to the large mammalian genomes. and even to larger data sets resulting from ultra-fast sequencing projects. The fact that the genome sequence need not be kept in main memory makes the program applicable to even larger data volumes in pan- or meta-genome projects. For demonstration, we have applied our program to a recent version of the NTdatabase (all non-redundant GenBank+EMBL+DDBJ+PD $B$ sequences, 21,789,632,349 bp). It requires 136 minutes and $40 \mathrm{MB}$ of main memory to compute all 15,560 unwords of length 14. A further interesting application would be for genomic fragment data. In meta-genome projects based on ultrafast sequencing technology, unwords analysis may prove useful in monitoring coverage.

Unwords, by definition, always have a fixed length (say $k$ ) in a given genome. Longer absent words may also be of interest. They are easily determined with our program: Adding all unwords as additional sequences to the genome and re-running the program, it will produce all absent words of length $k+1$, since they are the unwords of the extended genome.

No evidence has been collected for selection against specific words in a genome-wide fashion. Naturally, unwords tend to have atypical CG content in the AT-rich genomes we studied (see Table 4). CpG methylation and subsequent mutation favors unwords containing CG dinucleotides, and leads to an overabundance of their mutated variants [10]. These observations suggest that length and number of unwords, and in particular their deviation

Table 7: Unwords for the $D$. melanogaster genome.

\begin{tabular}{|c|c|c|c|}
\hline acccetaggga & accectctacg & acccggtaggg & accctaccggg \\
\hline acctagcgcgc & acctagcgcgt & acctagcgtga & acctaggtctg \\
\hline acgcgctaggt & acggecgtacc & acgggaggttc & acgtcccgeta \\
\hline actaggtaccg & aggcccgcgcg & aggcccgetat & agggtacgccg \\
\hline agtataggccg & atagcgggect & cacgcgtgggg & cagacctaggt \\
\hline ccccacgcgtg & ccceggectag & ccccgtagggc & cccgcgttaag \\
\hline cccggtagggt & cccggtctagg & cccgtacgcge & ccctaccgggt \\
\hline ccctacggggc & ccctaggcacg & ccggtagctag & ccggtagggta \\
\hline cctacgcgtca & cctacgtagag & cctagaccggg & cctagggtccg \\
\hline cctataggccg & cgcgcgggect & cgcgctagcgc & cgcgctaggcc \\
\hline cgcggggtacc & cgcgtagtcta & cgctagggccg & cggaccctagg \\
\hline cggecetagcg & cggcctatact & cggcctatagg & cggcgtaccet \\
\hline cggggeccgac & cgggtagactc & cgggtcgctag & cggtacctagt \\
\hline cggtcctatcc & cgtagaggggt & cgtccgtagca & cgtgagggacc \\
\hline cgtgcctaggg & ctagcgacccg & ctagctaccgg & ctaggccgggg \\
\hline ctctacgtagg & cttaacgcggg & gaacctcccgt & gacctactaga \\
\hline gacctaggtac & gacgctagggc & gagtctacccg & geccegtaggg \\
\hline gccctacgggg & gccctagcgtc & gcgcgctaggt & gcgcgtacccc \\
\hline gcgcgtacggg & gcgctagcgcg & gcggecctacc & gcgggtacccc \\
\hline gctagggtacc & ggataggaccg & ggcctagcgcg & gggacgttaga \\
\hline ggggtacccgc & ggggtacgcgc & ggtacccegcg & ggtaccctago \\
\hline ggtacggecgt & ggtagggccgc & ggtccctcacg & ggtccgcgeta \\
\hline gtaacgcggac & gtacctaggtc & gtccgcgttac & gtcgggecceg \\
\hline gtcggtcccta & taccctaccgg & tagactacgcg & tagcgeggaco \\
\hline tagcgggacgt & tagggaccgac & tcacgctaggt & tccetaggggt \\
\hline tctaacgtccc & tctagtaggtc & tgacgcgtagg & tgctacggacg \\
\hline
\end{tabular}


Table 8: Unwords for the S. cerevisiae genome.

\begin{tabular}{llll}
\hline cccegggga cgccecce cggggggeg tcccogggg \\
\hline
\end{tabular}

Table 9: Unwords for the S. aureus genome (strain MSSA476).

\begin{tabular}{|c|c|c|c|c|c|}
\hline aacceccc & acacgggg & accecgeg & acccgggc & acccgggg & accggcgg \\
\hline acgecggg & acgcgggc & acggeccg & acgggacc & acgggecc & acgggggg \\
\hline actccggg & actcgggc & agcccggg & agccgagg & aggeccec & aggecccg \\
\hline aggeccgg & aggggggg & atccgggg & cacggaga & cacgggge & cacggggg \\
\hline cagcgggg & caggccgc & caggccgg & cagggccg & ccacggag & cccacgga \\
\hline cccagggg & $\operatorname{cccccccc}$ & $\operatorname{ccccccct}$ & $\operatorname{ccccccgc}$ & $\operatorname{ccccccg} t$ & cccccggg \\
\hline cccecgtg & ccccgagg & $\operatorname{ccccg} g \mathrm{c}$ & cccegctg & ccccggag & ccceggat \\
\hline ccccggcc & ccccggeg & ccccgggc & ccccgggt & ccccgtgt & cccetggg \\
\hline cccgaggg & cccgcagg & cccgcggg & cccggagc & cccggagt & cccggegt \\
\hline cccgggag & cccgggec & cccggget & cccggggg & ccctaggg & cectecgc \\
\hline ccctcggg & ccgagagc & $\operatorname{ccgccccg}$ & ccgecggt & ccgcgecc & ccgcgcgg \\
\hline ccgcggge & ccggaccg & ccggeccg & ccggecga & ccggecgg & ccggectg \\
\hline ccggcggc & ccgggagc & ccgggecg & ccgggect & ccggggag & ccgggggc \\
\hline ccggtcag & cctcagcg & cctccgcg & cctccgga & cctcgceg & cctcggag \\
\hline cctcggct & cctcgggg & cctgcggg & cgacccce & cgagcccc & cgagcetc \\
\hline cgagctcg & cgceccga & $\operatorname{cgccccgc}$ & cgeccgeg & cgccgggc & cgecgggg \\
\hline cgcgcgga & cgcgcggc & cgcggagg & cgcggecg & cgcgggca & cgegggeg \\
\hline cgcggggt & cgetcccg & cgctgagg & cggaccce & cggacccg & cggagacc \\
\hline cggagecg & cggagggc & cggeccec & cggecceg & cggeccga & $\operatorname{cggeccgc}$ \\
\hline cggeccgg & cggecctc & cggecctg & cggecgac & cggecgeg & cggcgagg \\
\hline cggcgecc & cggcgecg & cggcgggc & cggetcce & cggctccg & cgggacce \\
\hline cgggagag & cgggagcc & cgggagcg & cgggeccg & cgggecgg & cgggecgt \\
\hline cggggcac & cggggecg & cggggect & cggggcgg & cgggggec & cgggtccg \\
\hline cggtccgg & ctacccec & ctcccogg & ctcccggg & ctccgacc & ctccgagg \\
\hline ctccgcgc & ctccggag & ctccgggg & ctccgtgg & ctcggecc & ctcgggac \\
\hline ctcgggcc & ctctcccg & ctgaccgg & ctggecec & gaggctcg & gagggecg \\
\hline gatcceta & gececcec & geccecgg & geccegtg & gcccgagt & geccgecc \\
\hline geccgecg & $\operatorname{gcccgcgc}$ & gcccgcgg & geccgcgt & gcccggeg & geccgggc \\
\hline gcccgggg & gcccgggt & gccetccg & gccgecgg & gccgegcg & gecggecc \\
\hline gegagecc & gcgcggag & gcgcgggc & gcgcgggg & gcggaggg & gcggecce \\
\hline gcggecgc & gcggectg & gcggctcc & gcgggecg & gcggggcg & gcgggggg \\
\hline gcggtcce & getccegg & gctccggg & gctctcgg & ggactccc & ggagccgc \\
\hline ggccagga & ggcecceg & ggcccgag & ggcccgga & ggcceggg & ggccggga \\
\hline ggccgggg & ggctcccg & gggaccgc & gggagccg & gggagtcc & gggatccc \\
\hline gggeccgt & gggccgag & gggecgca & gggecggc & gggcgecg & gggcgcgg \\
\hline gggcgggc & gggetcgc & ggggccag & ggggecge & ggggctcg & gggggecg \\
\hline gggggect & gggggggc & gggggggg & ggggggtt & gggggtag & gggggtcg \\
\hline ggggtccg & gggtaccc & gggtcceg & gggtccga & ggtccegt & ggtcggag \\
\hline ggtctccg & gtcccgag & gtcggecg & gtgecceg & tagggatc & tcceggec \\
\hline tccgcgcg & tccgcgga & tccggagg & tccgggec & tccgtggg & tcctggce \\
\hline tcggaccc & tcggccga & tcggecgg & tcgggecg & tcggggcg & tctccgtg \\
\hline tgccegcg & tgcggccc & & & & \\
\hline
\end{tabular}

Table 10: Unwords for the M. jannaschii genome.

$\begin{array}{lll}\text { cgatcg gegcgc gtcgac } & \end{array}$

Table I I: Unwords for the T. kodakarensis genome.

tactagta 
Table I2: Unwords for the M. genitalium genome.

\begin{tabular}{lllll}
\hline ceggec & cgegeg & ctcgga & ggcegg & tccgag \\
\hline
\end{tabular}

from expectation in random sequences, are statistical footprints of the process of real genome evolution. Mathematical models or reconstructions of genome evolution should be tested whether they produce a similar footprint.

The program UNWORDS is available from the Bielefeld University Bioinformatics Server [23]. While online use is restricted to sequence uploads of at most $5 \mathrm{Mb}$, the UNWORDS source code is available at [24], which has no such restriction.

\section{Authors' contributions}

RG designed and guided the study. SK provided two implementations of unword computation, one as an extension to VMATCH, and the UNWORDS program described here. $\mathrm{JH}$ ran the unword computations as well as all the additional analyses. All authors contributed to writing the article.

\section{Acknowledgements}

We are grateful to the anonymous referee who pointed us to the recent work of [9] and [10]. We thank Sven Rahmann and Ellen Baake for a discussion on unword statistics, and Jens Stoye for helpful discussions and his support for $\mathrm{JH}$ when the study was started. We appreciate the help of Jan Krüger and Daniel Hagemeier in composing the unwords website at BiBiServ.

\section{References}

I. Wang Y, Hill K, Singh S, Kari L: The spectrum of genomic signatures; from dinucleotides to chaps game representation. Gene 2005, 346: 173-185.

2. Workman C, Krogh A: No evidence that mRNAs have lower folding free energies than random sequences with the same dinucleotide distribution. Nucleic Acids Res 1999, 27(24):4816-4822.

3. Krause L, McHardy A, Nattkemper T, Pühler A, Stoye J, Meyer F: GISMO - gene identification using a support vector machine for ORF classification. Nucleic Acids Res 2007, 35(2):540-549.

4. Pingoud A, Jeltsch A: Structure and function of type II restriction endonucleases. Nucleic Acids Res 2001, 29:3705-3727.

5. Apostolico A, Bock ME, Lonardi S: Monotony of Surprise And Large-Scale Quest for Unusual Words. Proceedings of the Sixth Annual International Conference on Computional Biology (RECOMB 2002) 2002:22-31.

6. Apostolico A, Gong F, Lonardi S: Verbumculus and the Discovery of Unusual Words. Journal of Computer and Science Technology 2004, 19:22-41.

7. Darling A, Mau B, Blattner F, Perna N: Mauve: multiple alignment of conserved genomic sequence with rearrangements. Genome Res 2004, I4(7): I394-403.

8. Haubold B, Pierstorff N, Möller F, Wiehe T: Genome comparison without alignment using shortest unique substrings. BMC Bioinformatics 2005, 6:123.

9. Hampikian G, Andersen T: Absent sequences: nullomers and primes. Pacific Symposium on Biocomputing 2007, I 2:355-366.

10. Acquisti C, Poste G, Curtiss D, Kumar S: Nullomers: really a matter of natural selection. PLOS ONE 2007, 2(I0):

II. Abouelhoda M, Kurtz S, Ohlebusch E: Replacing Suffix Trees with Enhanced Suffix Arrays. Journal of Discrete Algorithms 2004, 2:53-86.
12. Vmatch [http://www.vmatch.de]

13. Rahmann S, Rivals $\mathrm{E}$ : On the distribution of the number of missing words in random texts. Combinatorics, Probability and Computing 2003, I 2:73-87.

14. Human Genome [http://www.ensembl.org/Homo sapiens]

15. Mouse Genome [http://www.ensembl.org/Mus musculus]

16. Drosophila Genomes [http://www.fruitfly.org/sequence/ release5genomic.shtml]

17. C. elegans Genome [http://www.ensembl.org/
C Caenorhabditis elegans]

18. Galagan J, Calvo S, Borkovich K, Selker E, Read N, Jaffe D, FitzHugh W, Ma L, Smirnov S, Purcell S, Rehman B, Elkins T, Engels R, Wang S, Nielsen C, Butler J, Endrizzi M, Qui D, lanakiev P, Bell-Pedersen D, Nelson M, Werner-Washburne M, Selitrennikoff C, Kinsey J, Braun E, Zelter A, Schulte U, Kothe G, Jedd G, Mewes W, Staben C, Marcotte E, Greenberg D, Roy A, Foley K, Naylor J, Stange-Thomann N, Barrett R, Gnerre S, Kamal M, Kamvysselis M, Mauceli E, Bielke C, Rudd S, Frishman D, Krystofova S, Rasmussen C, Metzenberg R, Perkins D, Kroken S, Cogoni C, Macino G, Catcheside D, Li W, Pratt R, Osmani S, DeSouza C, Glass L, Orbach M, Berglund J, Voelker R, Yarden O, Plamann M, Seiler S, Dunlap J, Radford A, Aramayo R, Natvig D, Alex L, Mannhaupt G, Ebbole D, Freitag M, Paulsen I, Sachs M, Lander E, Nusbaum C, Birren B: The genome sequence of the filamentous fungus Neurospora crassa. Nature 2003, 6934:82I-2.

19. S. cerevisiae Genome [http://www.ensembl.org/
[ Saccharomyces cerevisiae]

20. Fukui T, Atomi H, Kanai T, Matsumi R, Fujiwara S, Imanaka T: Complete genome sequence of the hyperthermophilic archaeon Thermococcus kodakaraensis KODI and comparison with Pyrococcus genomes. Genome Res 2005, I 5(3):352-63.

21. Bult CJ, White O, Olsen G], Zhou L, Fleischmann RD, Sutton GG, Blake JA, FitzGerald LM, Clayton RA, Gocayne JD, Kerlavage AR, Dougherty BA, Tomb JF, Adams MD, Reich Cl, Overbeek R, Kirkness EF, Weinstock KG, Merrick JM, Glodek A, Scott JL, Geoghagen NS, Venter JC: Complete genome sequence of the methanogenic archaeon, Methanococcus jannaschii. Science 1996, 273(5278): 1058-73.

22. Pobigaylo N, Wetter D, Szymczak S, Schiller U, Kurtz S, Meyer F, Nattkemper T, Becker A: Construction of a large signaturetagged mini-Tn5 transposon library and its application to mutagenesis of Sinorhizobium meliloti. Appl Environ Microbiol 2006, 72(6):4329-4337.

23. Computing Unwords on BibiServ [http://bibiserv.techfak.unibielefeld.de/unwords]

24. Unwords [http://www.zbh.uni-hamburg.de/unwords]

\section{Publish with Biomed Central and every scientist can read your work free of charge}

"BioMed Central will be the most significant development for disseminating the results of biomedical research in our lifetime. "

Sir Paul Nurse, Cancer Research UK

Your research papers will be:

- available free of charge to the entire biomedical community

- peer reviewed and published immediately upon acceptance

- cited in PubMed and archived on PubMed Central

- yours - you keep the copyright

Submit your manuscript here:

http://www.biomedcentral.com/info/publishing_adv.asp
BioMedcentral 